\title{
Accounting research: between natural science and practice
}

\author{
Frank G. H. Hartmann
}

Erasmus University, Rotterdam School of Management, Rotterdam, Netherlands.

Email: fhartmann@rsm.nl

\section{INTRODUCTION}

Over the years, I have become increasingly interested in the nature of accounting knowledge. This interest is not about getting satisfied by just finding another set of empirical hypotheses confirmed. Rather, it is about understanding how such empirical confirmations of theory consistent expectations form true accounting knowledge. My definition of true accounting knowledge extends the knowledge that we typically produce, exchange, and discuss in academic journals like the one you are reading. My definition of true accounting knowledge includes the accounting knowledge that actors in the world of accounting can actually put to use. My quest to understand the nature of this true accounting knowledge thus refers to the question about the scientific status of this knowledge, not merely in relation to the other academic fields of social and economic research, but also with regard to the accounting practice. I believe that an assessment of these qualities of the accounting research, especially of the type that has come to dominate current accounting journals, is timely and useful.

My thesis is built upon the consideration that empirical accounting research has developed over the last decades at a staggering speed in quantitative terms. Also in qualitative terms, it is easy to conclude that its development has been impressive. Even a short glance at the statistical sections of an average academic accounting paper today and such a paper of some decades ago suffices as comparison. It is less clear, however, that the relative positions of accounting research in the academic community have increased. Indeed, if we compare the ways in which the academic accounting discipline borrows from other academic disciplines and contributes to such other academic disciplines, the balance must be negative. Quantification of this comparison is difficult, but it seems safe to assert that the amount of theories and concepts that accounting researchers import from economics, psychology and even - today - neuroscience provides a stark contrast with the interest that economists, psychologists and neuroscientists have in accounting phenomena. The question whether this means that accounting research is stagnant, from an academic point of view, even despite its growth and development, is discussed and elaborated elsewhere (Basu, 2012; Moser, 2012; Waymire, 2012). Herein, I would like to spend a few words on the relation between accounting research and accounting practice.

It is clear that my definition of true accounting knowledge is normative. Connotations of the word 'true' are unavoidably positive and the implicit norm I would like to endorse is that accounting knowledge is usable by accounting practitioners. This seems an empty statement, but it is not. I believe that accounting practitioners have very little understanding of the current academic accounting research, nor do they seem to care about it. If our goal is to produce - through academic accounting research - to help create true accounting research, our first step would be to understand why this demarcation between academics and practitioners exists. In the remainder of this text, I will first make the case for my practice-oriented definition of true accounting knowledge. Then, I will propose a short analysis of the said demarcation, after which I will end this paper with a short conclusion.

\section{DEMARCATING ACCOUNTING RESEARCH FROM PRACTICE}

To some extent, the discussion I would like to stimulate in the accounting community resembles that in economics or at least that observed in some circles of economists.
Especially in continental Europe, economists have been dealing for a long time with a similar distinction between economics as an academic field of enquiry and economics 
as a usable theory of economic choice. Note a comment by Rothbard (1973, p. 31) on the status of academic economics:

Let the nonspecialist in economics pick up a journal article or monograph today and contrast it with one of a generation ago, and the first thing that will strike him is the incomprehensibility of the modern product. The older work was written in ordinary language and, with moderate effort, was comprehensible to the layman; the current work is virtually all mathematics, algebraic or geometric.

Let different things be different, but replacing 'economics' in the text above with 'accounting' keeps much of the intended message of this paper intact, disregarding for the moment the time-shift of more than four decades. Although the quote seems to critically address the increasing influence of mathematics in economics, which alienates the layman looking for economic advice, the problems lie deeper. One of those problems is that economics, or accounting, becomes a branch of mathematics, losing their own track, which results in second-best mathematics. Rothbard (1973, p. 31) quotes undisclosed economists, lamenting that:

[...] Economics nowadays often seems like a third-rate subbranch of mathematics, and one [...] that the mathematician himself does not esteem very highly.

A second and even more fundamental problem of the said development is that the relation between what counts as 'academic knowledge' and 'usable knowledge' becomes undefined. It is not so much a problem of the nonspecialist, who may simply lack the academic ability to understand mathematics, algebra, or geometry. Rather, the problem lies in the decreasing ability - or at least inclination - of academics to conduct their analyses with a subject specialist in mind. I would argue that much of our current academic work disregards the agency implications, i.e. the fact that knowledge should add to an agent's behavioural repertoire. Much of this development in economics is discussed as the question whether economics should be seen as a natural or as a social science. The implication of this distinction is that natural sciences should use naturalistic terms, which are easily subject to mathematical description. In contrast, social sciences make use of meaning-heavy constructs, for which mathematical analysis has little to offer. However, I believe that another framing of the question may be more useful to illustrate the cleavage between theory and practice in accounting. For accounting in particular, not just an expertise, but also an established profession, I propose that it is worthwhile to fundamentally consider the implicit levels of analysis we apply in our studies with regard to agency. With levels of analysis I mean those at which the theoretical patterns we aim to discover or interpret take place. Choosing a level of analysis fixates the phenomena of main interest, as well its causal antecedents and consequences. The following section illustrates the concept and its consequences for accounting research.

\section{THE THEORY-PRACTICE DEMARCATION AND LEVELS OF ANALYSIS IN ACCOUNTING RESEARCH}

Let us return to the accounting agent, the subject specialist, who has to deal with practical situations in which accounting knowledge may help determining a course of action. This agent may be a nonspecialist when it comes to understanding academic accounting research, but what is there to profit from current accounting research? I believe that distinguishing three levels of analysis in current accounting research helps to better understand how true accounting knowledge, as defined above, may differ from the accounting knowledge as produced, exchanged and discussed in the current mainstream academic accounting literature. The three levels of analysis relate to the personal , sub-personal, and supra-personal levels.

At the personal level of analysis (the accountant as a free agent), we would expect to find studies whose outcome immediately informs accountants about practical solutions to practical problems. Moreover, at this level of analysis, knowledge is cast in terms that are meaningful to the agent. This is not a trivial feature, as the issue of meaningfulness is itself a matter of deep philosophical debate in the social sciences. Nevertheless, the discussion is not just about the difference between hermeneutics and positivism. It is, quite simply, just one thing to conclude that accountants may suffer from social bias in decision making settings [Hartmann and Maas (2010) investigated under what conditions business unit (BU) controllers engaged in the creation of budgetary slack under social pressure. They found evidence of interactive effects of personality (Machiavellianism) involvement in decision making] and quite another thing to provide advice to 
accountants about how to solve, evade or avoid settings in which this might happen. In fact, the distinction between having knowledge about an agent and knowledge that is useful to the agent is fundamental, and far from trivial. It requires alignment between the accountants' and academic researchers' conceptualization of the accountants' work. In fact, however, practitioners talk about their work in trivial, 'folk', terms and academic researchers seem uneasy to deal with that, as it becomes evident from the predominance of psychology at this level of analysis. The question whose problem this is, the researcher's or the practitioner's, and what true accounting knowledge looks like should be firmly established in the agenda of accounting academics.

At the supra-personal level of analysis (the accountant as part of a larger system), we find academic output showing how accountants' behaviours operate in larger structures, such as economic markets. Typical examples include economic models of organizations or markets in which accountants or auditors function according to certain micro-economic patterns. These studies have mostly an 'as-if' approach. The behaviour of organizations and markets is explained through the agency of accountants, 'as-if' they were maximizing utility, averting risks, avoiding losses, and all that. Here the barrier between the academic analyses and the folk theory of the practitioner becomes more visible, not merely because of a fundamental difference in vocabulary, but rather in the outright denial of the accountant as an individual free-willed agent. The question here is how larger-system optimal structures can inform individual agents, and if they can whether they should follow this information. Again, the question comes up: what counts as true accounting knowledge here? In the light of space and time, I once more limit myself to raise the question as significant to accounting academics, without providing an answer.

Most recently, a third level of analysis has been introduced to the accounting literature, which lies at the sub-personal level of analysis (the accountant as a collection of internal processes). Under the explosive growth of cognitive and social neuroscience elsewhere, some early adopter papers have investigated neural, biological, drivers of accountant's agency (Eskenazi, Rietdijk, \& Hartmann, 2016). These authors build on Hartmann and Maas (2010), predicting that the effect of social pressure may be explained by the accountant's biological make-up. Mirror neuron system functionality is used to explain the accountants' vulnerability. Different from the personal level of analysis and similar to the supra-personal level of analysis, this sub-personal level of analysis does not provide immediate input for agency. In other words, and to give a practical example, it is simply impossible for an accountant to change the biological structure that, apparently, (co-)determines behaviour. However, the difference between sub- and supra-personal levels of analysis is fundamental. While the sub-personal aims to discover drivers of behaviour of the person, including such 'mystical' drivers as 'biases,' 'preferences,' and 'moods', and are therefore best understood as real constituents of personal behaviour, the supra-personal knowledge lacks this quality, both because of its 'as-if' nature and because of its (implicit) denial of individual agency. Overall, the knowledge consequences of this level for individual accounting agents also deserves fundamental scrutiny, even if the outcome is that true accounting knowledge cannot be defined as this level.

Casual observation provides many examples of accounting research conducted within one of the three levels of analysis just specified. While the above sketch is clearly incomplete in both overviewing relevant and informative accounting studies and in spelling out the consequences of the level of analysis view, it hopefully serves to provide a grid for the discussion about where on the continuum from natural science to folk practice we should place academic research aimed at true accounting knowledge.

\section{CONCLUSIONS}

It is not easy, and even quite risky, to generalize about accounting research and accounting researchers, as researchers and their research differ substantially in terms of scope, intellectual orientation, and research topic. However, I think it is fair to generally argue that the mere existence of academic accounting journals suggests that accounting is a topic of academic work that has at least some common characteristics in the large variety of accounting streams, themes and researchers. In this paper I have tried to establish a preliminary argument for a further understanding of the divide between accounting theory and accounting practice. Rather than imposing a view on how accounting research should be done or should be understood, I hope that the considerations concerning the levels of analysis in contemporary accounting research help our beautiful discipline to further 
advance, as they point to three distinct barriers between theory and practice, which may serve as clear targets for reconciliation. Accounting as a practical discipline is too important to accept its academic stagnation, even if only in the intellectual debate, as the pay-off of true accounting knowledge is potentially infinite (cf. Basu, 2012; Moser, 2012; Waymire, 2012).

\section{REFERENCES}

Basu, S. (2012). How can accounting researchers become more innovative? Accounting Horizons, 26(4), 851-870.

Eskenazi, P. I., Hartmann, F. G., \& Rietdijk, W. J. (2016). Why controllers compromise on their fiduciary duties: EEG evidence on the role of the human mirror neuron system. Accounting, Organizations and Society, 50, 41-50.

Hartmann, F. G., \& Maas, V. S. (2010). Why business unit controllers create budget slack: involvement in management, social pressure, and machiavellianism. Behavioral Research in Accounting, 22(2), 27-49.

Moser, D. (2012). Is accounting research stagnant? Accounting Horizons, 26(4), 845-850.

Rothbard, M. N. (1973). Praxeology as the method of the social sciences. Phenomenology and the Social Sciences, 2, 323-335.

Waymire, G. (2012). Introduction for essays on the state of accounting scholarship. Accounting Horizons, 26(4), 817-819. 